\title{
Identification of distinctive clinical significance in hospitalized patients with endoscopic duodenal mucosal lesions
}

Yeji Han ${ }^{1}$, Hye-Kyung Jung ${ }^{1}$, Ji Young Chang ${ }^{1}$, Chang Mo Moon ${ }^{1}$, Seong-Eun Kim ${ }^{1}$ Ki-Nam Shim Sung-Ae Jung ${ }^{1}$, Joo-Young Kim ${ }^{1}$, Ji-Yun Bae ${ }^{1}$, Sae-In Kim ${ }^{1}$, Ji-Hyun Lee ${ }^{1}$, and Sanghui Park ${ }^{2}$

Departments of ${ }^{1}$ Internal Medicine and ${ }^{2}$ Pathology, Ewha Womans University School of Medicine, Seoul, Korea

Received: May 27, 2015

Revised : July 13, 2015

Accepted: July 30, 2015

\section{Correspondence to}

Hye-Kyung Jung, M.D.

Department of Internal Medicine, Ewha Womans University Mokdong Hospital, 1071 Anyangcheon-ro, Yangcheon-gu, Seoul 07985 , Korea

Tel: +82-2-2650-2874

Fax: +82-2-2650-2874

E-mail:junghk@ewha.ac.kr
Background/Aims: Duodenitis is not infrequent finding in patient undergoing endoscopy. However, hospitalized patients have a higher incidence of secondary duodenal mucosal lesions that might be related with inflammatory bowel disease (IBD), cytomegalovirus (CMV) infection, tuberculosis, immunologic disorders, or other rare infections. We aimed to identify clinicopathologic features of duodenal mucosal lesions in hospitalized patients.

Methods: All hospitalized patients having duodenal mucosal lesions were identified by endoscopic registration data and pathologic data query from 2011 to 2014 . The diagnostic index was designed to be sensitive; however, a detailed review of medical record and endoscopic findings was undertaken to improve specificity. Secondary duodenal lesion was defined as having specific reason to explain the duodenal lesion.

Results: Among 6,334 hospitalized patients have undergone upper endoscopy, endoscopic duodenal mucosal lesions was detected in 475 patients. Secondary duodenal lesions was 21 patients (4.4\%) and the most frequent secondary cause was $\operatorname{IBD}(\mathrm{n}=7)$. The mean age of secondary group was significantly lower than that in primary group $(42.3 \pm 18.9$ years vs. $58.5 \pm 16.8$ years, $p=0.00$ ), and nonsteroidal anti-inflammatory drugs were less frequently used in secondary group, but there was no differences of gender or presence of Helicobacter pylori. The involvement of distal part of duodenum including postbulbitis or panduodenitis was more frequently detected in secondary group than in primary group. By multivariate regression analysis, younger age of 29 years and the disease extent were significant predictors for the secondary mucosal lesions.

Conclusions: Secondary duodenal mucosal lesions with different pathophysiology, such as IBD or CMV infection, are rare. Disease extent and age seems the most distinctive feature of secondary duodenal mucosal lesions.

Keywords: Duodenitis; Duodenal ulcer; Endoscopy; Inflammatory bowel diseases

\section{INTRODUCTION}

Duodenitis is defined as inflammation on the duode- nal mucosa and is not infrequent finding in patient undergoing endoscopy [1-4]. Endoscopic examination with histopathological evaluation can provide the un- 
derstanding of clinical meaningful lesions. Among 3,872 subjects who had undergone endoscopy for medical check-up, endoscopic duodenal mucosal lesions were detected in $21 \%$ and active/healing stage of duodenal ulcers were detected in $2.9 \%$ [5]. With expanded enforcement of endoscopy, many cases of inflammation on the duodenal mucosa are found among patients undergone endoscopy; however, its clinical significance is not definite.

In conventional concept, duodenitis has been perceived as precursor of duodenal ulcer and gastric hyperacidity is one of most significant causes in the spectrum of peptic ulcer disease $[6,7]$. Subsequently, Helicobacter pylori infection might have a strong causality in patients with duodenal ulcer; therefore, it has been suggested that gastric metaplasia in the duodenum and $\mathrm{H}$. pylori associated gastritis may be synergistic in the pathogenesis of duodenitis [8]. However, the prevalence of endoscopic duodenitis was similar for each study as $9 \%$ to $16 \%$, even though the prevalence of $\mathrm{H}$. pylori infection varies from studies in $28.9 \%$ to $75 \%$ [8-11].

A variety conditions are known to cause duodenal mucosal lesions including inflammatory bowel disease (IBD), tuberculosis, immunologic disorders, or other rare infections [12-17], especially, these secondary causes of duodenal lesions might be frequently detected in hospitalized patients. Upper gastrointestinal (GI) endoscopy is a useful and relatively non-invasive technique to diagnose duodenal mucosal lesion by causes other than $H$. pylori infection. It allows direct visualization of the mucosa for the acquisition of targeted biopsies to evaluate the severity and extent of intestinal inflammation.

We aimed to identify clinical and endoscopic features in hospitalized patients with duodenal mucosal lesions and to evaluate the predictors of clinically significant secondary duodenal mucosal lesions.

\section{METHODS}

\section{Case ascertainment}

From October 2011 to October 2014, 6,334 patients underwent the upper GI endoscope among hospitalized person at Ewha Womans University Mokdong Hospital. Patients with duodenal mucosal lesions were identified using a medical records linkage system including en- doscopic registration data and pathologic data query. A detailed chart review was undertaken to improve specificity by one experienced doctor (Y.H.) and ensure these cases actually had duodenal mucosal lesions.

We excluded patients younger than 18 years, patients with Brunner's gland hyperplasia, duodenal polyps, cysts, or subepithelial lesions. Ethics approval was obtained from the Institutional Review Board of Ewha Womans University Mokdong Hospital (EUMC 201707-058). This study was conducted in retrospective medical record review; therefore, there was no need to obtain the patient consent.

\section{Data collection and case definitions}

We performed several steps to ensure reliability and high quality. All information obtaining to diagnosis was recorded in specially designed standardized clinical data form. Demographic data as well as clinical data were collected from the medical records. In any uncertain cases, the endoscopic or pathologic findings were discussed with an experienced endoscopist (H.K.J.) and a pathologist (S.P.). The following information was collected from the review of medical records: (1) demographics including age at time of diagnosis and gender; (2) GI symptoms, including epigastric pain, abdominal pain, nausea, vomiting, dizziness, indigestion, bloating, poor oral intake, and alarm symptoms such as hematemesis, melena, hematochezia, chronic vomiting and weight loss; (3) comorbidities, including hypertensions, diabetes mellitus, pulmonary tuberculosis, IBD, malignancy, autoimmune disease, chronic renal failure; and (4) any medications that might possibly induce duodenal mucosal lesions, such as nonsteroidal anti-inflammatory drugs (NSAIDs), aspirin, anti-platelet agents, steroid, immunosuppressant, proton pump inhibitors were recorded.

Assessment of endoscopic findings was recorded in terms of erythema, hemorrhage, erosion, edema, and ulcer according to the following definitions [18-20]: (1) erythema was graded as followings: 0 , no lesion; 1 , distinctive color change of the patch; 2, a little more clear change in color of the patch; and 3, beef like reddish color detected; (2) hemorrhage was graded by number of hemorrhagic spots: o to 1, 2 to 5,6 to 10, and $\geq 10$; (3) erosion was graded by number of lesions: no erosion, 1 to 2,3 to 5 , and $\geq 6$; and (4) ulcer was categorized into three 
stage with its number: active, healing, and scar stage.

The extent of duodenal mucosal lesion was classified into three categories of bulb only, postbulbitis, and panduodenitis. The presence of $H$. pylori was detected with any of following methods: (1) rapid urease test; (2) urea breath test; (3) histological examination including H\&E staining or Giemsa staining; and (4) serologic test for $\mathrm{H}$. pylori antibody.

The duodenal mucosal lesions were categorized into primary and secondary lesion. Secondary duodenal mucosal lesions were defined as having underlying local or systemic causes; tuberculosis enteritis with/without active pulmonary tuberculosis, cytomegalovirus (CMV), Epstein-Barr virus, fungal, or parasite infection were diagnosed by histological examination including H\&E and special stain. For cases of medical history related with duodenal lesions, i.e., IBD including Crohn's disease or ulcerative colitis, radiation duodenitis, autoimmune diseases such as Henoch-Schonlein purpura (HSP), Bechet's disease, secondary lesion was defined as having histological findings with clinical manifes- tations. In these cases, histological re-examination was performed for the diagnostic ascertainment. Primary duodenal mucosal lesion was defined as cases without definitive underlying disease.

\section{Statistics analysis}

Descriptive and frequency analysis of the data from the study was expressed as counts, percentage, and mean \pm standard deviation. Chi-square test with exact test was used where applicable. Logistic regression was performed for univariate and multivariates analysis to evaluate the predictors for secondary duodenal mucosal lesions. $p$ values of $<0.05$ were considered to denote statistical significance. All data were analyzed using SPSS version 15.0 (SPSS Inc., Chicago, IL, USA).

\section{RESULTS}

\section{Patient's characteristics}

Among 6,334 hospitalized patients have undergone up-

Table 1. Patient's characteristics

\begin{tabular}{lccc}
\hline Characteristic & Primary duodenal lesions $(\mathrm{n}=454)$ & Secondary duodenal lesions $(\mathrm{n}=21)$ & $p$ value \\
\hline Age, $\mathrm{yr}$ & $58.5 \pm 16.8$ & $42.3 \pm 18.9$ & 0.00 \\
$<30(\mathrm{n}=26)$ & $19(4.2)$ & $7(33.3)$ & $7(33.3)$ \\
$30-49(\mathrm{n}=117)$ & $110(24.2)$ & $5(23.8)$ & \\
$50-69(\mathrm{n}=189)$ & $184(40.5)$ & $2(9.5)$ & 0.38 \\
$\geq 70(\mathrm{n}=143)$ & $141(31.1)$ & $15(71.4)$ & 0.00 \\
\hline Male sex & $281(61.9)$ & & 0.09 \\
Comorbidities $^{\mathrm{a}}$ & & $3(14.3)$ & 0.14 \\
\hline No comorbidities $(\mathrm{n}=142)$ & $143(31.5)$ & $2(9.5)$ & 0.00 \\
\hline Diabetes & $117(25.8)$ & $5(23.8$ & 0.31 \\
\hline Hypertension & $184(40.5)$ & $7(33.3)$ & 0.00 \\
\hline Inflammatory bowel disease ${ }^{\mathrm{b}}$ & 0 & $4(19.0)$ & 0.68 \\
\hline Malignancy & $54(11.8)$ & $4(19.0)$ & 0.02 \\
\hline Autoimmune disease & $8(1.8)$ & $6 / 13(46.2)$ & 0.59 \\
\hline Positive Helicobacter pylori & $108(40.5)$ & $1(4.7)$ & 0.03 \\
\hline NSAIDs or aspirin user & $127(27.9)$ & $18(94.7)$ & $2(9.52)$ \\
Any gastrointestinal symptoms & $359(79.3)$ & & \\
Alarm symptoms & $142(31.35)$ & & \\
\hline
\end{tabular}

Values are presented as mean $\pm \mathrm{SD}$ or number (\%).

NSAID, nonsteroidal anti-inflammatory drug.

${ }^{a}$ The data are not mutually exclusive.

${ }^{\mathrm{b}} \mathrm{The}$ most common cause of secondary duodenal lesion was inflammatory bowel disease $(\mathrm{n}=7)$. 
per endoscopy, 475 patients were diagnosed with endoscopic duodenitis or duodenal ulcers (Table 1). The primary duodenal mucosal lesion was observed in 454 patients (95.6\%) and secondary duodenal lesion was detected in 21 patients (4.4\%). The most frequent secondary cause was IBD $(n=7)$, and other causes include CMV infection $(\mathrm{n}=3)$, Bechet's disease $(\mathrm{n}=2), \operatorname{HSP}(\mathrm{n}=$ 2), radiation induced duodenitis $(n=2)$, Candida $(n=2)$, tuberculosis enteritis $(n=1)$, eosinophilic enteritis $(n=$ 1), and parasite infection ( $n=1)$ (Fig. 1).

In comparison of characteristics of primary and secondary duodenal lesions, the mean age of secondary group was significantly lower than that of primary group ( $42.3 \pm 18.9$ years vs. $58.3 \pm 16.8$ years, $p=0.000$ ). The proportion of patients under age of 30 in the secondary group was higher than that in the primary group $33.3 \%$ vs. $4.2 \%, p=0.001$ ). However, there was no significant difference observed by gender. Pulmonary tuberculosis and chronic renal failure are more prevalent in primary group compared to secondary group, but no difference in having diabetes mellitus, hypertension, or malignancy. $H$. pylori was similarly detected in both primary and secondary group (40.3\% vs. $46.2 \%, p=0.682$ ). The proportion of usage of NSAIDs or aspirin was significantly higher in the primary group than the secondary one (27.9\% vs. $4.7 \%, p=0.019)$.

There were any GI symptoms in $79.4 \%$ of primary du-

6,334 Search in endoscopic registration data and pathologic data query: adults, 2011-2014

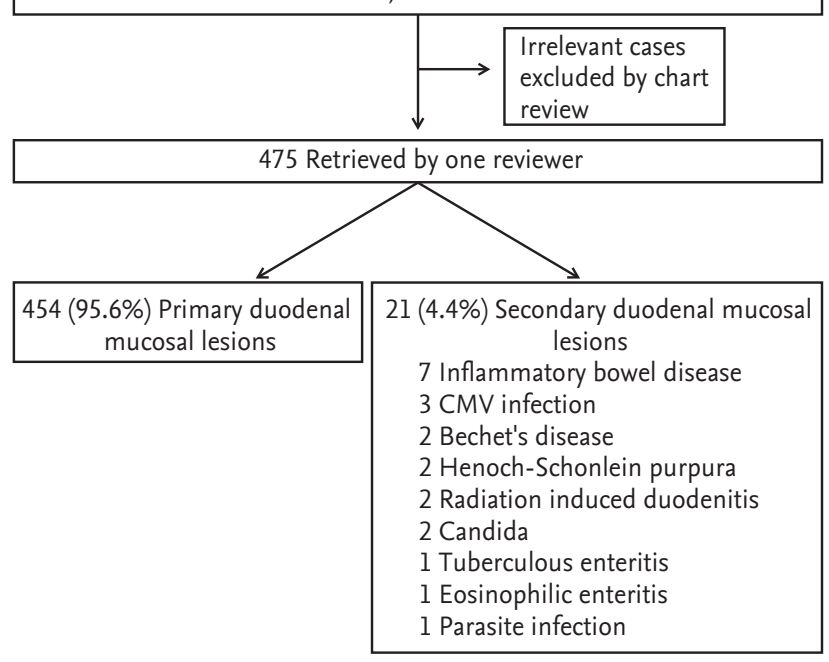

Figure 1. Flow chart of patient's selection. CMV, cytomegalovirus. odenal lesion and $85.7 \%$ of secondary lesion. Especially, abdominal pain was more commonly detected in the secondary lesion compared to primary lesion, but it did not reach the statistical significance $(24.0 \%$ vs. $57.1 \%, p=$ 0.06). The frequency of alarm symptoms such as vomiting or GI bleeding in the primary group was significantly higher than that in the secondary (31.4\% vs. 9.52\%, $p=0.033)$.

\section{Difference of endoscopic findings between primary and secondary duodenal lesions}

Clinical aspects of endoscopic finding in each patient group indicated significant difference in some respect (Table 2). According to the extent of the lesion, involvement of distal part of duodenum including postbulbitis or panduodenitis was more frequently detected in secondary lesions than in the primary lesions (30.0\% vs. $5.2 \%, p=0.000$ ) (Fig. 2). Ulcerative lesions, including active or healing stage of ulcer, were similarly detected in primary and secondary lesions ( $38.4 \%$ vs. 50.0\%, $p=0.717$ ).

The severity of duodenitis was measured by the degree of erythematous mucosal changes, number of hemorrhage or erosions (Fig. 3). The erythematous mucosal changes were most frequently accompanied findings in both groups (96.7\% vs. $95.2 \%$ ) and hemorrhages or erosive mucosal lesions were rarely detected in both group. There was no difference of the severity of duodenitis between two groups. In patients with IBD, while various types from active inflammation to chronic inflammation were discovered, mainly nonspecific inflammation was recorded although cryptitis was accompanied in $2 / 6$ patients (Fig. 4). Furthermore, granuloma which implies direct invasion of Crohn's disease was not observed.

\section{Univariate and multivariate analysis of predictors for secondary duodenal lesions}

Table 3 shows result of univariate logistic regression analysis used to identify the predictors for secondary duodenal lesions. The young age under 30 years increased the odd for the secondary lesions compared to the elderly ( $\geq 70$ years). The involvement of second portion of duodenum or panduodenitis was significantly related with secondary lesion, and the presence of active duodenal lesions was significantly related with the primary duodenal lesions. By multivariate analysis, young age of 30 years old and the extent of mucosal lesions 
Table 2. Characteristics of duodenal ulcer in primary and secondary duodenal mucosal lesions

\begin{tabular}{|c|c|c|c|}
\hline Characteristic & Primary duodenal lesions $(\mathrm{n}=454)$ & Secondary duodenal lesions $(\mathrm{n}=21)$ & $p$ value \\
\hline Duodenal ulcer & $138(30.5)$ & $8(38.1)$ & \\
\hline Stage & & & 0.717 \\
\hline Active/healing & $53(38.4)$ & $4(50)$ & \\
\hline Scar & $31(28.4)$ & $4(50)$ & \\
\hline Number & & & 0.118 \\
\hline Single & $115(83.3)$ & $7(87.5)$ & \\
\hline Multiple & $23(21.8)$ & $1(12.5)$ & \\
\hline \multicolumn{4}{|l|}{ Grade of duodenitis ${ }^{\mathrm{a}}$} \\
\hline Erythema & & & 0.161 \\
\hline o & $15(3 \cdot 3)$ & $1(5.0)$ & \\
\hline 1 & $424(93.6)$ & $18(85.71)$ & \\
\hline 2 & $14(3.1)$ & $2(9 \cdot 52)$ & \\
\hline Hemorrhage & & & 0.366 \\
\hline o & $445(98.0)$ & $15(93.8)$ & \\
\hline $1-2$ & $4(0.9)$ & $1(6.2)$ & \\
\hline $3-4$ & $5(1.1)$ & o & \\
\hline Erosions & & & 0.336 \\
\hline o & $447(98.4)$ & $20(95.2)$ & \\
\hline$\leq 4$ & $4(0.9)$ & o & \\
\hline$\geq 5$ & $3(0.7)$ & $1(6.2)$ & \\
\hline
\end{tabular}

Values are presented as number (\%).

${ }^{\mathrm{a}} \mathrm{Grade}$ of duodenitis was based on the endoscopic findings including erythema, hemorrhage, and the number of erosions.

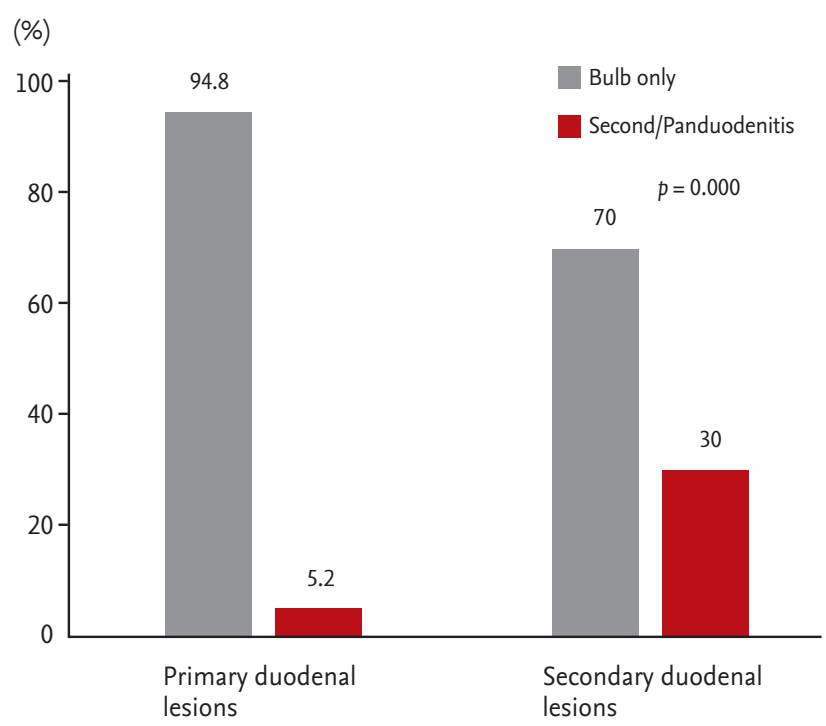

Figure 2. Difference of disease extent of duodenum between primary and secondary duodenal mucosal lesions. Involvement of distal part of duodenum including postbulbitis or panduodenitis is more frequently detected in secondary lesions than in the primary lesions (30.0\% vs. $5.2 \%, p=0.000)$. were significant predictors for the presence of secondary duodenal mucosal lesions.

\section{DISCUSSION}

The present study revealed that there is clinical distinction to categorize primary and secondary duodenal mucosal lesions. The majority of patients had normal duodenal mucosa or nonspecific duodenitis; however, in some cases, these duodenal lesions might be related with clinical significance. The secondary duodenal mucosal lesions related with specific pathogenesis was frequently detected in young age group and manifested in distal part of duodenum including panduodenitis or postbulbitis.

There was no significantly different observation made for existence of clinical symptoms between primary and secondary lesions. However, observation of alarm symptom was lower in its frequency in secondary group than that in the primary group while distribution of lesion 
was higher in regions beyond bulb. This observation implies that duodenal lesion discovered in parts other than bulb by endoscopy can be more related to other specific
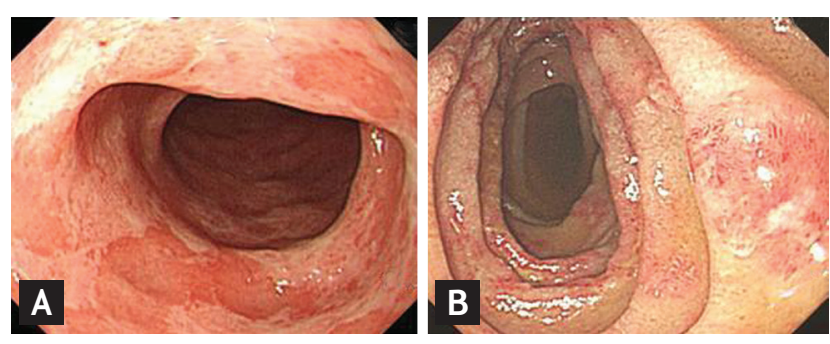

Figure 3. Endoscopic duodenal finding of secondary duodenal lesions. (A) Henoch-Schonlein purpura. (B) Eosinophilic enteritis. Both lesions are detected in second portion with shallow and diffuse mucosal lesion.
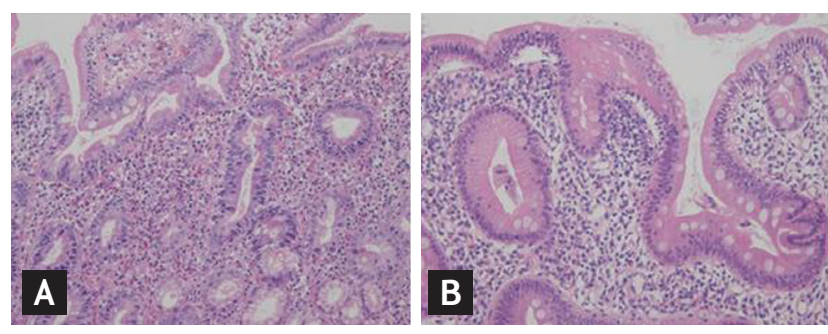

Figure 4. Pathologic finding of duodenal biopsy in duodenal lesion with inflammatory bowel disease patients. Various types from active inflammation to chronic inflammation are discovered. (A) Chronic inflammation. Dense lymphoplasmacytic infiltration with a few eosinophils is noted (H\&E, $\times 200$ ). (B) Chronic active inflammation with cryptitis. Acute mixed inflammatory infiltrate is identified (H\&E, $\times 200)$. etiology. The previous study which reviewed pathology and clinical behavior of patients diagnosed with peptic duodenitis in 2nd part, more than $80 \%$ of the patients were diagnosed with celiac disease (54.1\%) in Western country [21]. It may be difficult to apply this result to our study as case of celiac disease is extremely rare for Koreans. However, it is already known that more cases of duodenal lesion accompanying autoimmune disease such HSP are found in 2nd than in bulb [16,22].

There were several studies in recent with effort to identify the meaning of duodenal lesion in IBD. It is noteworthy that $H$. pylori infection rate is substantially lower and frequency of duodenitis is higher in IBD patients compared to these in general population [23,24]. In our study, one out of seven IBD patients accompanied duodenal ulcer had $H$. pylori infection. While the cause of low $H$. pylori infection rate in IBD has not been clearly identified, it might be suggested with long-term use of sulfasalazine or 5 -aminosalicylic acid causing bacterial eradication $[24,25]$. Granuloma is rarely observed in patients with Crohn's disease and it is consistent with the previous study [24]. Comparative analysis with other neighboring clinical specimen is important in order to identify focal inflammation sign [25-27]. However, it is difficult to determine duodenal involvement of IBD by histopathological evaluation and $H$. pylori negative upper GI lesion by routine endoscopy was high in $30 \%$ to $70 \%$ of Crohn's disease patients without symptoms

Table 3. Univariate and multivariate analysis for predictors of secondary duodenal lesions

\begin{tabular}{|c|c|c|c|c|}
\hline \multirow{2}{*}{ Variable } & \multicolumn{2}{|c|}{ Univariate } & \multicolumn{2}{|c|}{ Multivariate } \\
\hline & OR (95\% CI) & $p$ value & OR $(95 \%$ CI $)$ & $p$ value \\
\hline \multicolumn{5}{|l|}{ Age, yr } \\
\hline$\leq 29$ & $26.83(5.2-139.2)$ & 0.00 & $15.2(1.1-208.9)$ & 0.04 \\
\hline $30-49$ & $4.47(0.91-22.0)$ & 0.07 & $2.68(0.23-31.8)$ & 0.44 \\
\hline $50-69$ & $1.94(0.37-10.1)$ & 0.43 & $2.06(0.18-23.3)$ & 0.56 \\
\hline$\geq 70$ & 1.0 & & 1.0 & \\
\hline Male sex & $1.51(0.58-4.0)$ & 0.40 & $3.30(0.52-21.5)$ & 0.21 \\
\hline Helicobacter pylori & $0.79(0.26-2.4)$ & 0.68 & $0.68(0.16-3.0)$ & 0.45 \\
\hline \multicolumn{5}{|c|}{ Extent of duodenal lesions } \\
\hline Proximal part & 1.0 & - & 1.0 & - \\
\hline Distal part ${ }^{\mathrm{a}}$ & $3.3(2.7-22.1)$ & 0.00 & $11.82(1.88-74 \cdot 3)$ & 0.02 \\
\hline Active duodenal ulcer & $2.6(1.01-7.6)$ & 0.00 & $3.4(0.5-21.2)$ & 0.19 \\
\hline
\end{tabular}

OR, odds ratio; CI, confidence interval.

${ }^{\mathrm{a}}$ Involvement of distal part of duodenum including panduodenitis or postbulbitis. 
$[26,28]$. There is controversy whether to view these duodenal lesions as Crohn's disease involvement. However, mononuclear cell infiltration on duodenal mucosal biopsy was more frequently observed in Crohn's disease and it was related with the increased level of proinflammatory cytokine, such as interleukin 6 [26].

Duodenal mucosal lesion has been generally perceived as peptic disease, and it has been proved in number of studies that $H$. pylori was more frequently detected in duodenal ulcer patients compared to control group [29,30]. However, in large scale multicenter study in the United States, H. pylori was detected in $40.5 \%$ of primary duodenal lesion and $46.2 \%$ of secondary duodenal lesion. There showed no significant difference in infection rate between two groups, and the rate was similar to $59.6 \%$ of general population [31]. While the prevalence of duodenitis was not significantly different in developing countries, in which $H$. pylori is noticeably high $[4,32]$. This result implies that $H$. pylori infection might not be the only main cause of duodenitis.

The present study suggests that one of the distinctive factors to classify secondary duodenal lesion from primary is age. The incidence rate of duodenal lesion accompanying other disease was significantly higher in the younger age group than the patient group with primary duodenal lesion. A study found that rate of upper GI involvement in IBD has tendency to increase with lower age when other variables are controlled; however, precise cause has not been clearly identified although it can be related to onset age of the disease [25].

There are some potential limitations of this study. This study was conducted with retrospective manner and misclassification might have reduced the secondary duodenal mucosal lesions because duodenal biopsy might not be performed in all cases of endoscopic duodenitis, although we took every step to minimize this issue. Many studies have been conducted to correlate endoscopic finding of duodenitis and pathologic diagnosis; however, conclusion of such studies are divergent [33-37]. It is important to enforce the endoscopy and biopsy together for an accurate diagnosis.

In conclusion, there is a rare overlap with duodenal lesions of different pathogenesis including IBD or autoimmune disorders. However, duodenal involvement of distal part of duodenum or duodenal lesions in young age seems distinctive features of duodenal mucosal le- sions associated with other underlying pathophysiology.

\section{KEY MESSAGE}

1. Nonspecific duodenitis are frequently detected; however, in some cases, these duodenal lesions are related with clinical significance.

2. Secondary duodenal mucosal lesions associated with specific pathogenesis such as inflammatory bowel disease, cytomegalovirus infection, autoimmune diseases are commonly found in young inpatients and appear as panduodenitis or postbulbitis.

\section{Conflict of interest}

No potential conflict of interest relevant to this article was reported.

\section{REFERENCES}

1. Levine MS, Turner D, Ekberg O, Rubesin SE, Katzka DA. Duodenitis: a reliable radiologic diagnosis? Gastrointest Radiol 1991;16:99-103.

2. Hasan M, Hay F, Sircus W, Ferguson A. Nature of the inflammatory cell infiltrate in duodenitis. J Clin Pathol 1983;36:280-288.

3. Hasan M, Sircus W, Ferguson A. Duodenal mucosal architecture in non-specific and ulcer-associated duodenitis. Gut 1981;22:637-641.

4. Pounder RE, Ng D. The prevalence of Helicobacter pylori infection in different countries. Aliment Pharmacol Ther 1995;9 Suppl 2:33-39.

5. Jung HK, Kim SE, Shim KN, Jung SA. Association between dyspepsia and upper endoscopic findings. Korean J Gastroenterol 2012;59:275-281.

6. Thomson WO, Joffe SN, Robertson AG, Lee FD, Imrie CW, Blumgart LH. Is duodenitis a dyspeptic myth? Lancet 1977;1:1197-1198.

7. Classen M, Koch H, Demling L. Duodenitis: significance and frequency. Bibl Gastroenterol 1970;9:48-69.

8. Taha AS, Dahill S, Nakshabendi I, Lee FD, Sturrock RD, Russell RI. Duodenal histology, ulceration, and Helicobacter pylori in the presence or absence of non-steroidal anti-inflammatory drugs. Gut 1993;34:1162-1166.

9. Walker TD, Karemera M, Ngabonziza F, Kyamanywa P. 
Helicobacter pylori status and associated gastroscopic diagnoses in a tertiary hospital endoscopy population in Rwanda. Trans R Soc Trop Med Hyg 2014;108:305-307.

10. Shrestha R, Koirala K, Raj KC, Batajoo KH. Helicobacter pylori infection among patients with upper gastrointestinal symptoms: prevalence and relation to endoscopy diagnosis and histopathology. J Family Med Prim Care 2014;3:154-158.

11. Wee A, Kang JY, Ho MS, Choong HL, Wu AY, Sutherland IH. Gastroduodenal mucosa in uraemia: endoscopic and histological correlation and prevalence of helicobacterlike organisms. Gut 1990;31:1093-1096.

12. Tytgat GN. The Sydney System: endoscopic division. Endoscopic appearances in gastritis/duodenitis. J Gastroenterol Hepatol 1991;6:223-234.

13. Theis VS, Sripadam R, Ramani V, Lal S. Chronic radiation enteritis. Clin Oncol (R Coll Radiol) 2010;22:70-83.

14. Pratap A, Cerda SR, Varghese JC, Oviedo JA. Duodenal tuberculosis. Gastrointest Endosc 2006;64:648-649.

15. Wilcox CM, Schwartz DA. Symptomatic CMV duodenitis: an important clinical problem in AIDS. J Clin Gastroenterol 1992;14:293-297.

16. Kato S, Shibuya H, Naganuma H, Nakagawa H. Gastrointestinal endoscopy in Henoch-Schonlein purpura. Eur J Pediatr 1992;151:482-484.

17. Endo K, Kuroha M, Shiga H, et al. Two cases of diffuse duodenitis associated with ulcerative colitis. Case Rep Gastrointest Med 2012;2012:396521.

18. Dixon MF, Genta RM, Yardley JH, Correa P. Classification and grading of gastritis: the updated Sydney System. International Workshop on the Histopathology of Gastritis, Houston 1994. Am J Surg Pathol 1996;20:1161-1181.

19. Pazzi P, Gamberini S, Scagliarini R, Dalla Libera M, Merighi A, Gullini S. Misoprostol for the treatment of chronic erosive gastritis: a double-blind placebo-controlled trial. Am J Gastroenterol 1994;89:1007-1013.

20. Kato T, Araki H, Onogi F, et al. Clinical trial: rebamipide promotes gastric ulcer healing by proton pump inhibitor after endoscopic submucosal dissection. A randomized controlled study. J Gastroenterol 2010;45:285-290.

21. Leonard N, Feighery CF, Hourihane DO. Peptic duodenitis: does it exist in the second part of the duodenum? J Clin Pathol 1997;50:54-58.

22. Gunasekaran TS, Berman J, Gonzalez M. Duodenojejunitis: is it idiopathic or is it Henoch-Schonlein purpura without the purpura? J Pediatr Gastroenterol Nutr 2000;30:22-28.
23. Halme L, Karkkainen P, Rautelin H, Kosunen TU, Sipponen P. High frequency of helicobacter negative gastritis in patients with Crohn's disease. Gut 1996;38:379-383.

24. Halme L, Rautelin H, Leidenius M, Kosunen TU. Inverse correlation between Helicobacter pylori infection and inflammatory bowel disease. J Clin Pathol 1996;49:65-67.

25. Sonnenberg A, Melton SD, Genta RM. Frequent occurrence of gastritis and duodenitis in patients with inflammatory bowel disease. Inflamm Bowel Dis 2011;17:39-44.

26. Kuriyama M, Kato J, Morimoto N, Fujimoto T, Okada H, Yamamoto K. Specific gastroduodenoscopic findings in Crohn's disease: comparison with findings in patients with ulcerative colitis and gastroesophageal reflux disease. Dig Liver Dis 2008;40:468-475.

27. Oberhuber G, Puspok A, Oesterreicher C, et al. Focally enhanced gastritis: a frequent type of gastritis in patients with Crohn's disease. Gastroenterology 1997;112:698-706.

28. Annunziata ML, Caviglia R, Papparella LG, Cicala M. Upper gastrointestinal involvement of Crohn's disease: a prospective study on the role of upper endoscopy in the diagnostic work-up. Dig Dis Sci 2012;57:1618-1623.

29. Borch K, Jonsson KA, Petersson F, Redeen S, Mardh S, Franzen LE. Prevalence of gastroduodenitis and Helicobacter pylori infection in a general population sample: relations to symptomatology and life-style. Dig Dis Sci 2000;45:1322-1329.

30. Vaira D, Miglioli M, Mule P, et al. Prevalence of peptic ulcer in Helicobacter pylori positive blood donors. Gut 1994;35:309-312.

31. Kim N, Kim JJ, Choe YH, et al. Diagnosis and treatment guidelines for Helicobacter pylori infection in Korea. Korean J Gastroenterol 2009;54:269-278.

32. Yang H, Dixon MF, Zuo J, et al. Helicobacter pylori infection and gastric metaplasia in the duodenum in China. J Clin Gastroenterol 1995;20:110-112.

33. Wilkinson SP. The limits of endoscopy in the diagnosis of oesophagitis, gastritis and duodenitis. Aliment Pharmacol Ther 1997;11:13-17.

34. Jenkins D, Goodall A, Gillet FR, Scott BB. Defining duodenitis: quantitative histological study of mucosal responses and their correlations. J Clin Pathol 1985;38:1119-1126.

35. Naik SR, Joshi VV, Khuroo MS, Mehta SK. Comparison of endoscopic and histological features of duodenitis. Indian J Gastroenterol 1985;4:149-151.

36. Lewis S, Stableforth W, Awasthi R, et al. An examination of the relationship between the endoscopic appearance 
of duodenitis and the histological findings in patients with epigastric pain. Int J Clin Exp Pathol 2012;5:581-587.

37. Elta GH, Appelman HD, Behler EM, Wilson JA, Nostrant
TJ. A study of the correlation between endoscopic and histological diagnoses in gastroduodenitis. Am J Gastroenterol 1987;82:749-753. 